\title{
El género textual "etiqueta" y su dimensión multimodal
}

\author{
Gisella Policastro Ponce \\ CB Lingua \\ gisellapolicastro@gmail.com \\ https://dx.doi.org.10.12795/futhark.2018.il3.04
}

Fecha de recepción: 10.07.2018

Fecha de aceptación: 15.09.2018

Resumen: El acto comunicativo, y más particularmente, el sistema lingüístico, tal y como lo conocemos hoy en día, se caracterizan por presentar una relación de dependencia entre todos los elementos de construcción expresiva destinados a cumplir determinadas funciones comunicativas dentro de un contexto sociocultural determinado y que concurren en un sincretismo multimodal (García Asensio et al., 2015). Los recientes avances en el campo de la Teoría Multimodal, motivados por los avances de la era de la digitalización, han estimulado la necesidad de profundizar en su conocimiento, así como en su aplicación a diferentes disciplinas, tales como la Lingüística, la Traducción, el Análisis del Discurso, la Semiótica, entre otras, en la medida que se observa una transformación de las estructuras discursivas por medio de múltiples articulaciones. Partiendo de la perspectiva multimodal del texto, el presente estudio tiene por objeto identificar la etiqueta como un género textual en sí mismo (Coutinho y Miranda, 2009) y poner de manifiesto la dimensión multimodal de la etiqueta. Atendiendo a estas consideraciones, se analizarán las particularidades que justifican la consideración de este microtexto como un género textual propiamente dicho y se identificará la dimensión multimodal de la etiqueta.

Palabras clave: Teoría Multimodal, género textual, etiqueta, sistema lingüístico, Semiótica.

\section{Product label as a textual genre itself and its multimodal dimension}

\begin{abstract}
Communicative act and, in particular, linguistic system, as we know it today, are characterized by a relation of dependence between all the elements of expressive construction aimed to fulfill certain communicative functions within a
\end{abstract}


determined sociocultural context, and they concur in a multimodal syncretism (García Asensio et al., 2015). Recent developments in the field of Multimodal Theory, motivated by the advances of the era of digitalization, emphasized the need to deepen their knowledge, as well as its application to different disciplines, such as Linguistics, Translation, Analysis of Discourse, Semiotics, among others, to the extent that a transformation of discursive structures is observed through multiple articulations. From a multimodal perspective of the text, the present study aims to identify the label as a textual genre itself (Coutinho and Miranda, 2009) and highlight its multimodal dimension. Based on these considerations, the particularities which justify the consideration of this microtext as a textual genre will be analyzed, and the multimodal dimension of the label will be identified.

Key words: Multimodal Theory, textual genre, label, linguistic system, Semiotics.

Sumario: I. Introducción. 2. El género textual «etiqueta». 3. La dimensión multimodal del género textual «etiqueta». 4. Conclusión.

\section{Introducción}

Según Halliday (2000), el lenguaje ha evolucionado a lo largo de los siglos en función de las necesidades comunicativas de cada generación; por consiguiente, cumple una función específica en cada contexto y refleja la forma de organización de cada cultura. Consideramos, por tanto, que el lenguaje es un elemento social, una realidad cambiante y evolutiva, del mismo modo que el hombre es un ser social que necesita del lenguaje para comunicarse e interrelacionarse con los demás individuos. Esta concepción social de la actividad comunicativa y de todas las piezas que entran en juego solo puede comprenderse desde una interpretación del lenguaje multimodal: el texto como hecho comunicativo que cumple una función social, relacionada íntimamente con una situación dada y una meta concreta definida por el emisor (Alexopoulou, 201 I: 98).

En los escenarios comunicativos del mundo moderno se experimentan constantes transformaciones que dan lugar a diferentes situaciones de hibridación discursiva, dando muestras de una evolución de los géneros discursivos y una fusión de los modos de expresión, mediante la inclusión de nuevas relaciones e implementación de nuevos recursos comunicativos. En el presente estudio partimos de la premisa de que dichas renovaciones han sido fruto de la implementación de los recursos multimodales en las estructuras discursivas y, por tanto, el concepto actual de texto únicamente puede entenderse desde una perspectiva multimodal analizado en sociedad, como una: 
Unidad lingüística comunicativa fundamental, producto de la actividad verbal humana, que posee carácter social. Se caracteriza por su cierre semántico y comunicativo y por su coherencia, debida a la intención comunicativa del hablante de crear un texto íntegro, y a su estructuración mediante dos conjuntos de reglas: las de nivel textual y las del sistema de la lengua. (Bernárdez, 1982: 95)

De la definición propuesta por Bernárdez, podemos deducir una triple dimensión textual (dimensión comunicativa, pragmática y estructural), en la que el texto se concibe como un hecho comunicativo creado para cumplir una función social y una finalidad determinada:

a) Dimensión sociocomunicativa. El carácter social del texto queda determinado por la intercomunicación entre emisor/productor y receptor/lector dentro de un proceso de comunicación, que es el fin último de todo texto. Según señala Payrató (1998: 68-69) para comprender la comunicación debemos admitir que ésta respeta un sistema $\circ$ una estructura, que se fundamenta en funciones previsibles y bien definidas, aunque no exista ninguna entidad que la regule, porque realmente se rige por la propia naturaleza sociocomunicativa del hombre.

b) Dimensión pragmática. Hace referencia a los elementos extralingüísticos que se encuentran presentes en cualquier manifestación comunicativa. El texto, como tal, queda condicionado por dichos componentes que influyen en su producción, interpretación o estructura. El enfoque multimodal del lenguaje únicamente puede comprenderse a partir de la concepción de una estructura textual en la que intervienen una serie de factores $y$ aspectos externos (espacio-temporales, contextuales, socioculturales) además de la propia lengua en sí misma. Esta dimensión es puramente multimodal.

c) Dimensión estructural. Esta dimensión se refiere a la organización necesaria para considerar a un texto como tal y engloba los conceptos de coherencia y cohesión. La estructura textual permite la organización del contenido dentro de un esquema determinado y según unos parámetros establecidos, de modo que faciliten la clasificación de los modelos textuales.

A la luz de lo anterior, podemos hablar de un modelo de organización del discurso renovado, mediante la clasificación de tipos textos concebidos en base a una serie de características lingüísticas, sintagmáticas, paradigmáticas y estructurales específicas y comunes dispuestas de acuerdo con las convenciones que impone el 
contexto en que aparece y con base en una fusión de varios modos de expresión sobre un único recurso textual.

En lo que a este estudio concierne, una de las cuestiones centrales que trataremos de resolver en este trabajo es la consideración de la etiqueta como género textual en sí mismo. Existe una interrelación indiscutible entre las convenciones "género discursivo» y «tipo de texto», y como afirma García Izquierdo (2002: 17) «es obvio, pues, que para la correcta definición de un género deberemos describir también qué tipo de texto lo vehicula habitualmente en la lengua de trabajo». Con el propósito de delimitar las fronteras que delimitan su significado, y arrojar algo más de luz sobre nuestro planteamiento, consideramos oportuno introducir brevemente dichos conceptos:

\section{a) Género discursivo}

El uso de la lengua se lleva a cabo en forma de enunciados (orales y escritos) concretos y singulares que pertenecen a los participantes de una u otra esfera de la praxis humana. Estos enunciados reflejan las condiciones específicas y el objeto de cada una de las esferas no solo por su contenido (temático) y por su estilo verbal, o sea por la selección de los recursos léxicos, fraseológicos y gramaticales de la lengua, sino, ante todo, por su composición o estructuración. (...)La riqueza y diversidad de los géneros discursivos es inmensa, porque las posibilidades de la actividad humana son inagotables y porque en cada esfera de la praxis existe todo un repertorio de géneros discursivos que se diferencia y crece a medida de que se desarrolla y se complica la esfera misma. Aparte hay que poner de relieve una extrema heterogeneidad de los géneros discursivos (orales y escritos) (Bajtín, 1982).

La anterior reflexión en torno al concepto de «género» del teórico ruso Baijtín, precursor del estudio del discurso y del texto y pionero en formular la teoría de los géneros discursivos, acentúa las relaciones entre la organización textual, la construcción del conocimiento y las prácticas sociales del lenguaje. Los géneros discursivos hacen referencia a «un conjunto de enunciados relativamente estables ligados a una esfera social determinada» (Bajtín, 1982) y, por tanto, son representantes empíricos de las actividades del lenguaje dentro del contexto en el que aparecen. Por un lado, los géneros se encuentran vinculados a las diferentes prácticas sociales discursivas que originan una enorme variedad de textos estructurados según unas convenciones establecidas y que determinan la selección de recursos lingüísticos y estructurales en función del objetivo perseguido.

Los modelos discursivos, en tanto que hechos socioculturales y discursivos con un objetivo claro, se configuran y fundamentan en funciones previsibles y bien definidas; sin embargo, están de igual modo sujetos a variación, de acuerdo con las modificaciones que imponga el contexto y en respuesta a los cambios históricos y sociales que dan lugar a la aparición de nuevos géneros textuales. 
Los géneros discursivos comparten los mismos parámetros contextuales, funciones y rasgos lingüísticos, se producen dentro de un ámbito específico, reflejan la esfera social de cada individuo y para su producción es necesario «tomar en consideración las finalidades, los actores, los temas propios de ese ámbito y, como consecuencia, las formas verbales y no verbales propias y adecuadas para cada caso» (Calsamiglia y Tusón, 1999: 253)

\section{b) Tipologías textuales}

Los géneros discursivos se materializan en diversos tipos de texto, según la voluntad del productor. Por tanto, una vez determinado el género discursivo, el siguiente paso será identificar el tipo de texto. A diferencia del género, la tipología textual responde a un repertorio cerrado e invariable de varias modalidades textuales, que varían ligeramente según las escuelas y enfoques. En una clasificación textual coexisten los géneros discursivos y los tipos de texto, en tanto que a cada género le corresponde un tipo de texto y a cada tipo una gran variedad de géneros.

La clasificación de los textos ha seguido pautas muy diversas en función de las tendencias y corrientes dominantes $y$, del gran abanico de modelos planteados, consideramos más apropiado la metodología propuesta por Werlich (1979), fundamentada sobre la base de características semánticosintácticas. Las «bases temáticas», concepto utilizado por Werlich para denominar los cinco tipos básicos de estructuración, combinan la dimensión cognitiva y lingüística y las relaciona con las pretensiones del hablante y sus actividades cognitivas. La clasificación de Werlich combina los modos de abordar la realidad con los modos de representarla, teniendo en cuenta el contexto extralingüístico y los aspectos de la estructura sintáctica, tal y como se detalla a continuación:

\begin{tabular}{|l|l|}
\hline TIPOS DE BASES & \multicolumn{1}{|c|}{ FINALIDAD } \\
\hline Base descriptiva & Expresan ocurrencias y cambios en el espacio. \\
\hline Base narrativa & $\begin{array}{l}\text { Expresan desarrollos temporales/causales de las } \\
\text { acciones en el tiempo. }\end{array}$ \\
\hline Base expositiva & $\begin{array}{l}\text { Explican representaciones conceptuales (sintéticas } \\
\text { o analíticas) }\end{array}$ \\
\hline Base argumentativa & Expresan una toma de posición o juicio de valor. \\
\hline Base directiva & $\begin{array}{l}\text { Indican acciones para el comportamiento del } \\
\text { hablante o del destinatario. }\end{array}$ \\
\hline
\end{tabular}

Tabla I. Bases temáticas propuestas por Werlich (1979).

$\begin{array}{ll}\text { Futhark I3 (20|8) } & \mathbf{6 9} \\ 65-78 & \end{array}$


Como queda patente tras lo expuesto con anterioridad, es posible hacer un planteamiento tipológico organizado en torno a un número limitado de categorías dentro de un alto nivel de abstracción que sirva de cimiento para plantear y definir una clasificación de tipologías textuales que implica tener en cuenta una multitud de criterios heterogéneos y que dan lugar a una sinfín de categorías en constante evolución; sin olvidar que aunque existe una distinción entre ambos conceptos, se trata de categorías interrelacionadas.

En el presente trabajo proponemos un modelo de análisis asentado sobre un estudio complementario que sea capaz de dar cuenta de la multiplicidad de facetas que el texto plantea. Este enfoque integra varios niveles en la descripción de la tipología textual trazando un modelo de análisis multidimensional del texto.

A nuestro juicio, el texto objeto de análisis, es decir, la «etiqueta» sobrepasa todos los límites de clasificación textual, obligando a desarrollar una nueva forma de aproximación en el análisis del discurso, como procederemos a analizar en el siguiente apartado.

\section{El género textual «etiqueta»}

El análisis del discurso de la etiqueta presenta planteamientos amplios y complejos que son la causa de una hibridación discursiva que tiene lugar en su naturaleza interna.

El análisis de una etiqueta, aunque por muy simple que parezca, plantea un gran desafío en este complicado, competitivo y propagandístico mundo comercial. No sólo se encarga este pequeño soporte de cumplir unas expectativas como facilitar al consumidor la información suficiente del producto que va adquirir o consumir brindando información útil al usuario final, sino que el papel de la etiqueta además debe incorporar un efecto «llamada de atención», que capte los deseos, la atención del comprador, apelando a sus sentidos. Un aspecto adicional a tener en cuenta es que todo tipo de etiquetado, sea promocional o no, debe cumplir una serie de requisitos normativos, estipulados por cada industria o sector de comercialización y cada país de distribución.

De acuerdo con lo anterior, se desprende que la etiqueta constituye una unidad textual singular, que combina diferentes elementos propios de diversos géneros y tipologías textuales que interaccionan en su producción. Al objeto de evidenciar que la etiqueta cumple en sí misma con la definición de «texto» propiamente dicho, abordaremos la triple dimensión textual propuesta por Bernárdez (1982), anteriormente citada, e identificaremos su funcionalidad en la etiqueta. 
1. Función sociocomunicativa. La etiqueta satisface con una doble necesidad social intrínseca de informar y persuadir al consumidor sobre un producto determinado. La finalidad informativa pretende satisfacer el reclamo por parte del comprador actual, cada vez más interesado en conocer los productos que consume, como consecuencia de una preocupación social generalizada por la salud y el cuidado personal. Esta acción determina una intercomunicación entre el emisor y el receptor, por cuanto el etiquetado representa el único canal de comunicación entre ambos. Por su parte, la finalidad persuasiva del etiquetado es parte de su esencia. La razón de ello es que el producto se elabora con el fin de ser consumido; sin embargo, su comercialización en un mercado globalizado, plural y competitivo exige la recurrencia a expresiones persuasivas (elemento lingüístico) y efectos visuales (elementos extralinguísticos) que sorprendan y atraigan al consumidor potencial. La etiqueta representa la pieza fundamental de cualquier artículo que identifica el contenido del mismo, brinda un servicio informativo al cliente, representa la imagen del producto en sí mismo y de la propia empresa, crea un vínculo entre el consumidor y el fabricante $y$ viste al producto para alcanzar su pretensión primordial: llegar al consumidor.

2. Función pragmática. El etiquetado es la consecuencia de un trabajo conceptual dentro del sistema lingǘstico, toda vez que crea una interrelación y dependencia con los componentes interpretativos. Todos los componentes extralingüisticos de una etiqueta cumplen un objetivo concreto, que a su vez está determinado no solo por el propósito comunicativo sino también por los requisitos normativos aplicables. Dentro del lenguaje del etiquetado se utilizan parámetros extralingüísticos comunes: gráficos, colores, formas, imágenes, fórmulas, etc., considerando que cada componente debe transmitir al consumidor un tipo de mensaje, no solo relativo a la dimensión pragmática, sino también a la dimensión sociocomunicativa y a la dimensión estructural, ya que cada elemento de la etiqueta está dispuesto y determinado por y para un motivo o función concreta, en definitiva que llegue al consumidor de una forma estructural y linguïstica más impactante, con el empeño de atraer el interés del consumidor a través de las vías sensoriales $y$ visuales $y$ satisfacer sus exigencias informativas. 
3. Función estructural. Esta función determina cómo se debe disponer la información sociocomunicativa y pragmática de forma que impacte directamente en el consumidor. Este microtexto está limitado en gran medida por el espacio, un factor que determina cómo se debe diseñar, organizar y plantear el formato de la etiqueta con la intención de transmitir la información requerida y captar el interés del consumidor. Asimismo, el factor y propósito comunicativo de cada recurso lingüístico o extralingüístico es parte de la función estructural de la etiqueta, debiendo responder a las necesidades informativas y publicitarias asociadas a su consumo. Por último dentro de esta dimensión estructural se debe respetar la obligatoriedad del cumplimiento de la normativa vigente, establecida en función del sector que se trate y del país en el que se comercialice.

La combinación de estas funciones se configura dentro del etiquetado creando una textualidad interdisciplinar que hace de la etiqueta un texto híbrido y resalta su atractivo desde el punto de vista lingüístico y multimodal (un aspecto que trataremos en el siguiente apartado), revelando un gran abanico de posibilidades para un análisis de la etiqueta como género textual en sí mismo.

Siguiendo a García Izquierdo (2007), «pocos son los conceptos que han suscitado tanta controversia como el concepto de género», si bien no por ello, o quizás precisamente por esta razón, profundiza en su estudio, en tanto que considera que:

los géneros sirven para la automatización de los procesos cognitivos y más concretamente, entre otras cosas, para detectar información implícita o explícita, comprender conceptos e ideas claves, identificar las relacio nes conceptuales y la fuerza locucional del texto original o desarrollar los procesos de comprensión, memoria y atención (Montalt, Ezpeleta \& García Izquierdo (2008) apud. Conde, 2014: 169)

Conceptualizar la realidad a través del lenguaje es uno de los principales rasgos que caracterizan al género, y es precisamente la función que cumple la etiqueta, valiéndose de diversos mecanismos seleccionados a partir de una infinita variedad de recursos comunicativos, unidades lingüísticas, categorizaciones y procesos comunicativos, entre otros, y un conjunto de parámetros con los que delimitar la realidad. Una realidad que, tal y como atribuyó Saussure (2004) al sistema lingüístico, es cambiante y dinámica. La lengua evoluciona del mismo modo que lo hace la realidad, como reflejo o bien como condicionante de la misma, «la actividad de lenguaje es a la vez el lugar y el medio de las interacciones sociales constitutivas de todo conocimiento humano» (Bronckart 1997: 337); y en esta 
disyuntiva «se elaboran los mundos discursivos que organizan y semiotizan las representaciones sociales del mundo» (ídem.)

Nuestra argumentación del género textual de la etiqueta se sostiene en lo anteriormente expuesto y culmina en la siguiente conceptualización de García Izquierdo (2005):

\begin{abstract}
el género es una categoría aplicable a cualquier ámbito de comunicación, puesto que es un producto colectivo, resultado de cada circunstancia concreta de comunicación y, por tanto, cualquier forma de texto convencionalizada y determinada culturalmente, independientemente del ámbito (especializado o no) en que se inscriba la comunicación, se podrá considerar un género.
\end{abstract}

\title{
3. La dimensión multimodal del género textual «etiqueta»
}

El ser humano no sólo codifica la realidad cuando hace uso de la lengua, sino que lo hace cuando escucha ruidos, música, ve las acciones o los gestos o cuando observa imágenes y colores, entre otras opciones disponibles (Kress y van Leeuwen, 200I).

Todo acto de comunicación está condicionado por relaciones de interacción social que trascienden de una intención común propia del ser humano y su forma de comunicarse con los demás, ya sea de forma oral o escrita, mediante la recurrencia a formas de comunicación progresivamente más variadas e innovadoras.

La lengua es un elemento vivo, que está en constante cambio, y evoluciona de manera directamente proporcional al modo en lo hace el ser humano; son los usuarios los que diseñan las exigencias comunicativas y los expertos del lenguaje los que tratan de satisfacer sus necesidades. Hoy en día, la lengua es vista «como el producto de un proceso social ॥ (Halliday 1982: 42) y representa el punto de partida para el análisis de cualquier forma de comunicación.

En la medida en que se incorporan nuevos recursos comunicativos, emergen nuevos géneros discursivos y tipologías textuales, con miras a contribuir a una mejor identificación y clasificación textual, que facilite su comprensión. Y así surge el género textual «etiqueta», según lo abordaremos en este apartado.

A finales del siglo $X X$, los enfoques pragmáticos delimitaron nuevos objetos de investigación en torno a la interacción del ser humano con el medio, mediante el contacto sensorial entre la mente y el mundo, construyendo nuevos sistemas de comunicación que sobrepasaban la dimensión lingüística, desarrollando códigos expresivos visuales, acústicos o táctiles. 
Estos hallazgos sugirieron una transformación en el modo de concebir la conceptualización del texto, alejándose del paradigma monomodal en el que el sistema de comunicación se reducía casi exclusivamente al lenguaje como elemento predominante del fenómeno comunicativo. Al ponerse en duda la definición tradicional de «texto», se comienza a cuestionar el modo de concebir los procesos de codificación y descodificación de un mensaje y a dar forma a nuevos criterios de significación comunicativa, en los que tienen cabida múltiples modalidades expresivas, siguiendo nuevos criterios interpretativos, funcionales y estructurales.

En el contexto de estos planteamientos revolucionarios, se desarrollan diferentes corrientes y ramas disciplinarias que se instauran en contraposición al enfoque tradicional monomodal, tales como la Semiótica Social y del Texto y la Lingüística Textual, que asientan las bases para el establecimiento de la Teoría Multimodal.

El marco teórico multimodal se consolida gracias a una motivación generalizada de alejamiento de la teoría monomodal que facilita el avance hacia nuevas líneas de investigación que desafían las modalidades lingüísticas hasta entonces consolidadas, dando paso a nuevas formas de representación de la realidad expresiva. Las nociones de texto, discurso, comunicación o lenguaje comienzan a ser objeto de renovación por medio de la transformación multimodal que continua experimentando constantes trasformaciones en la actualidad.

Durante las últimas décadas, las nuevas tendencias tecnológicas y electrónicas han invadido la esfera del lenguaje y de la comunicación, sometiéndola a condicionamientos extralingüísticos de diversa índole (recursos semióticos, recursos visuales, recursos iconográficos, gestos, música, lenguaje oral, entre otros). Esta evolución y concepción actualizada de la comunicación lingüística ratifica la necesaria presencia de la Teoría Multimodal que se fundamenta sobre la base de múltiples articulaciones comunicativas que transforman las estructuras discursivas y los modelos semióticos disponibles en nuestra realidad social.

La Teoría Multimodal nos lleva a la convicción de que existe un conjunto de modos semióticos presentes en cualquier tipo de comunicación, haciéndose imprescindible y muy necesario utilizar e identificar todos los recursos que nos ofrece esta ciencia para poder entender cualquier tipo de acto comunicativo o mensaje. De ahí que a la hora de analizar una etiqueta nos encontremos con representaciones tanto lingüísticas como extralingüísticas, que nos llevan a la transmisión de un conocimiento mediante los recursos multimodales, cargados de significación. Nuestra mente percibe determinados estímulos visuales a través de los sentidos o de la información extrasensorial, que se traducen en nuestra mente en códigos o sistemas de comunicación. (Levesque y Brachman, 1987). 
En lo que respecta a nuestro ámbito de estudio en particular, la representación multimodal de los elementos presentes en una etiqueta se entiende como un proceso mediante el cual las unidades que integran un área específica son sustituidas por elementos gráficos, símbolos o imágenes. Estos elementos se corresponden con diversos sistemas de comunicación que son codificados mediantes signos percibidos por nuestros sentidos. El análisis del género textual «etiqueta» desde una dimensión multimodal se vale necesariamente de la semiótica para la transmisión de información, utilizando signos que representan un lenguaje visual, entendidos como «cualquier cosa que representa a otra a través del lenguaje visual« (Acaso 2006: 38). Estos signos se extraen a partir de tres elementos: el significante $\circ$ el «elemento diseñado»; el referente, «lo que representa el significante» y el pattern, que hace referencia al «conjunto de características conceptuales que establecen la relación entre significante y referente» (Groupe, 1993).

En el marco de la teoría de Sevilla y Sevilla (2003: 194), estos autores consideran que a través de una metodología interpretativa de códigos no verbales se podría determinar un paralelismo entre la estructura del texto no verbal y la forma en que se deben articular los conceptos que se empleen en dichos códigos. Su propuesta nos ha parecido la más próxima al enfoque de nuestro planteamiento y la más ilustrativa, con el fin de identificar los recursos multimodales y las funciones semióticas presentes en las etiquetas, estructurando el modo en el que interactúan y se integran con el lenguaje.

Al objeto de identificar la presencia de dichos significantes multimodales en cualquier tipo de etiqueta, tomaremos como referencia la metodología propuesta de Sevilla y Sevilla (2003) y la triple dimensión textual de Bernárdez (1982), descrita con anterioridad:

a) Dimensión estructural. El espacio disponible para la etiqueta dependerá del tamaño del producto, por tanto, puede variar en función del mismo; sin embargo, suele ser reducido. Por consiguiente, la organización de la información, el contenido informativo que se desee incluir, el diseño o el modo en que se desee captar la atención del consumidor quedan limitados por el tamaño de la etiqueta. Teniendo en cuenta, además, que la misión comunicativa tiene por objeto apelar de forma directa en el consumidor, resulta vital que lo visual cobre protagonismo. Los recursos multimodales de tipo visual son capaces de transmitir las intenciones comunicativas de forma precisa, ocupando el menor espacio posible y mediante diversas formas de manifestación (color, disposición, tipo de fuente, elementos iconográficos, imágenes, 
etc.). Debe existir una interrelación entre las representaciones lingüísticas y extralingüísticas, de manera que se cumplan los criterios de coherencia y cohesión mínimos.

b) Dimensión sociocomunicativa. La finalidad informativa y persuasiva se materializa en la etiqueta en virtud de la combinación entre las representaciones lingüísticas y no lingüísticas. En términos generales, la función referencial se manifiesta en recursos lingüísticos y la función apelativa se expresa a través de elementos multimodales.

c) Dimensión pragmática. Puede ocurrir que, en determinados casos, ciertos elementos multimodales sean más efectivos que el propio lenguaje para conceptualizar la realidad, bien porque sean más cercanos al concepto que se desee representar 0 bien porque nuestra mente los asocie de un modo más directo a representaciones de tipo gráfico. El potencial comunicativo de dichos recursos confirma la necesidad de la utilización de recursos multimodales en las etiquetas, en combinación con la codificación de la información a través del lenguaje verbal. Esta dimensión supone un esfuerzo y un estudio claramente profundo de todos y cada uno de los elementos que se incorporan en las etiquetas, dedicando especial atención a las exigencias comerciales y normativas aplicables.

\section{Conclusión}

Hemos dejado atrás la centralidad del lenguaje verbal $y$, a partir de la perspectiva multimodal, nos basamos en la idea de que el significado es producido, distribuido, interpretado y (re)aprovechado a través de muchos modos de representación y comunicación (Kress y Van Leeuwen, 200I).

Se confirman por tanto los hallazgos previos y, con ello, se contribuye a la evidencia de la incorporación de las etiquetas como parte de un género textual y a la imposibilidad de entender el género «etiqueta» si no se concibe a partir de una perspectiva multimodal.

Como parte fundamental de cualquier tipo de producto, la etiqueta presta un servicio al cliente al tiempo que ejerce de elemento identificativo del producto, desempeñando un papel publicitario y comercial, todo ello dentro de un panorama de recursos lingüísticos y semióticos muy variado, rico y completo.

Partiendo de una aparente simpleza de un microtexto que se presenta un soporte convencional, el análisis de la dimensión multimodal del genero textual 
«etiqueta» se fundamenta en la peculiaridad de disponer una combinación de elementos lingüísticos característicos de diferentes tipologías textuales, demostrando una relación de dependencia entre todas las unidades que interactúan en su producción.

\section{Referencias bibliográficas}

ACASO, M. (2006). El lenguaje visual. Barcelona: Paidós.

ALEXOPOULOU, A. (20ll). El enfoque basado en los géneros textuales y la evaluación de la competencia discursiva En: Del texto a la lengua: La aplicación de los textos a la enseñanza-aprendizaje del español L2-LE 97II0). Asociación para la Enseñanza del Español como Lengua Extranjera. Disponible en: https://dialnet.unirioja.es/servlet/articulo?codigo $=5419275$

BAITIN, M. (I 982). Estética de la creación verbal, Buenos Aires: Siglo XXI.

BERNÁRDEZ, E. (1982). Introducción a la Lingüística del Texto. Madrid: Espasa Calpe.

BRONCKART, J. P. (1997) Activité langagière, textes et discours. Pour un interactionisme socio-discursif. Paris: Delachaux et Niestlé.

CALSAMIGLIA, H. y TUSÓN, A. (1999): Las cosas del decir, Barcelona, Ariel.

CONDE, T. (20l4). Traducción, géneros textuales y enfoques cognitivos. Hermeneus. Revista de la Facultad de Traducción e Interpretación de Soria. Disponible en: https://recyt.fecyt.es/index.php/HS/article/view/33267

COUTINHO, M. A. y MIRANDA, F. (2009). To describe textual genres: problems and strategies. Genre in a Changing World. Perspectives on Writing. Colorado: The WAC.

COUTINHO, A. (20I0). Las etiquetas como género de texto - un abordaje comparativo. Vino, lengua y traducción. Disponible en: https://novaresearch.unl.pt/en/publications/las-etiquetas-comog\%C3\%A9nero-de-texto-un-abordaje-comparativo.

GARCÍA, M. Á., POLANCO, F., YÚFERA, I. (2015). Mecanismos multimodales de focalización de la información en la prensa digital del campo científico y jurídico: la negrita. Universidad de Alicante: Estudios de Lingüística. Disponible en: http://hdl.handle.net//0045/529/2

GARCÍA, I. (2002). El género: plataforma de confluencia de nociones fundamentales en didáctica de la traducción. Revista Discursos, Série Estudos de Tradução, [Versión de Gentt]. Disponible en: http://www.gentt.uji.es/Publicacions/IGarcia_Lisboa.pdf. (2005). El género y la lengua propia: el español de especialidad. En García Izquierdo, I. (Ed.), El género textual y la traducción: reflexiones teóricas y aplicaciones pedagógicas. Berna: Peter Lang. 
(2007). Los géneros y las lenguas de especialidad. En Alcaraz Varó, E., Martínez, J. M. y Yus Ramos, F. (Eds.), Las lenguas profesionales y académicas (I 19-125). Barcelona: Ariel.

(20II). Competencia textual para la traducción. Valencia: Tirant lo Blanch.

GARCÍA IZQUIERDO, I. y MONZÓ, E. (2003). Una enciclopedia para traductores. Los géneros de especialidad como herramienta privilegiada del traductor profesional. En Muñoz Martín, R. (Ed.), I AlETI. Actas del I Congreso Internacional de la Asociación Ibérica de Estudios de Traducción. [Versión de Gentt]. Disponible en: http://www.gentt.uji.es/Publicacions/IGarciaEMonzo 03.pdf

HALLIDAY, M.A.K. (1982 [1978]). El lenguaje como semiótica social. Interpretación social del lenguaje y del significado. México: Fondo de Cultura Económica.

(2000). Design and transformation: New theories of meaning. London: Routledge.

KRESS, G. Y VAN LEEUWEN, T. (2006). Reading Images: The Grammarof Visual Design. London/ New York: Routledge

(200I). Multimodal Discourse: the Modes and Media of Contemporary Communication. London: Edgard Arnold.

LEVESQUE H. J.; BRACHMAN R. J. (1987). Expressiveness and tractability in knowledge representation and reasoning. Comput Intell. Disponible en: http://www.inf.unibz.it/ franconi/dl/course/2006/articles/BrachLev.pdf.

PAYRATÓ, L. (1998), Oralment. Estudis de variació funcional, Barcelona: Publicacions de l'Abadia de Montserrat.

SAUSSURE, F. (1915-196I) Curso de Lingüística General. Buenos Aire: Losada. (2004) Escritos sobre lingüística general. Barcelona: Gedisa.

SEVILLA, M. Y SEVILLA, J. (2003). Una clasificación del texto científico-técnico desde un enfoque multidireccional. Language Design. Disponible en: https://dialnet.unirioja.es/ejemplar/ I I4167

(1999). La aplicación de los gráficos en la didáctica de la traducción científico-técnica. Didáctica. Lengua y Literatura. Revistas Científicas Complutenses. Disponible en: https://revistas.ucm.es/index.php/DIDA/article/view/DIDA9999। I0I45A.

WERLICH E. (1979). Typologie der Texte. $2^{\mathrm{a}}$ edición. Heidelberg: Queller and Meyer. 